\title{
Genetic and environmental relationships of detailed milk fatty acids profile determined by gas chromatography in Brown Swiss cows
}

\author{
S. Pegolo, ${ }^{*}$ A. Cecchinato, ${ }^{* 1}$ J. Casellas, $†$ G. Conte,$\ddagger$ M. Mele, $\ddagger$ S. Schiavon, ${ }^{*}$ and G. Bittante* \\ *Department of Agronomy, Food, Natural resources, Animals and Environment (DAFNAE), University of Padova, Viale dell'Università 16, \\ 35020 Legnaro, Padova, Italy \\ †Departament de Ciència Animal i dels Aliments, Universitat Autònoma de Barcelona, 08193 Bellaterra, Spain \\ ‡Department of Agricolture, Food and Environment, Università di Pisa, Via del Borghetto, 80, 56124 Pisa, Italy
}

\section{ABSTRACT}

The aim of this study was to characterize the profile of 47 fatty acids, including conjugated linoleic acid (CLA), 13 fatty acid groups, and $5 \Delta^{9}$-desaturation indices in milk samples from Brown Swiss cows. The genetic variation was assessed and the statistical relevance of the genetic background for each trait was evaluated using the Bayes factor test. The additive genetic, herd-date, and residual relationships were also estimated among all single fatty acids and groups of fatty acids. Individual milk samples were collected from 1,158 Italian Brown Swiss cows and a detailed analysis of fat percentages and milk fatty acid compositions was performed by gas chromatography. Bayesian animal models were used for (co)variance components estimation. Exploitable genetic variation was observed for most of the de novo synthesized fatty acids and saturated fatty acids, except for C4:0 and C6:0, whereas long-chain fatty acids and unsaturated fatty acids (including CLA) were mainly influenced by herd-date effects. Herd-date effect explained large portions of the total phenotypic variance for C18:2 cis-9, cis-12 (0.668), C18:3 cis-9,cis-12,cis-15 (0.631), and the biohydrogenation and elongation products of these fatty acids. The desaturation ratios showed higher heritability estimates than the individual fatty acids, except for CLA desaturation index (0.098). Among the medium-chain fatty acids, C12:0 had greater heritability than C14:0 (0.243 vs. 0.097, respectively). Both C14:0 and C16:0 showed negative additive genetic correlations with the main monounsaturated and polyunsaturated fatty acids of milk fat, suggesting that their synthesis in the mammary gland may be influenced by the presence of unsaturated fatty acids. No correlation was observed between $\mathrm{C} 4: 0$ and the other short-chain fatty acids (except for C6:0), confirming the independence of C4:0 from de novo mammary fatty acid synthesis. Among

Received March 19, 2015

Accepted October 24, 2015.

${ }^{1}$ Corresponding author: alessio.cecchinato@unipd.it the genetic correlations dealing with potentially beneficial fatty acids, C18:0 was positively correlated with vaccenic and rumenic acids and negatively with linoleic acid. Finally, fatty acids C6:0 through C14:0 showed relevant correlations due to unknown environmental effects, suggesting the potential existence of genetic variances in micro-environmental sensitivity. This study allowed us to acquire new knowledge about the genetic and the environmental relationships among fatty acids. Likewise, the existence of genetic variation for most of de novo synthetized fatty acids and saturated fatty acids was also observed. Overall, these results provide useful information to combine feeding with genetic selection strategies for obtaining a desirable milk fatty acids profile, depending on the origin of fatty acids in milk.

Key words: Brown Swiss, genetic parameters, Bayes factor, fatty acids, $\Delta^{9}$-desaturation index

\section{INTRODUCTION}

Milk and dairy products are sources of energy, highquality protein, fat, minerals, and vitamins (Demment and Allen, 2003; Rooke et al., 2010). Bovine milk contains around 3 to $5 \%$ fat, represented 95 to $98 \%$ by triglycerides, which are in turn composed of glycerol and fatty acids. The fatty acid component is composed of 50 to $70 \%$ SFA, 20 to $40 \%$ of MUFA, and 1 to $5 \%$ PUFA (Jensen, 2002). The fatty acid composition of milk influences the milk's nutritional value and technological properties and reflects the cow's metabolic status (Fleischer et al., 2001; Mulligan et al., 2006). Recent data also suggest that it may reflect the cow's $\mathrm{CH}_{4}$ production, as moderate relationships have been found between $\mathrm{CH}_{4}$ production and some fatty acids (Chilliard et al., 2009; Dijkstra et al., 2011; van Lingen et al., 2014). Various feeding, management, and breeding strategies can be applied to manipulate the fatty acids profiles of milk (Lock and Bauman, 2004; Shingfield et al., 2013) and of processed milk products (Cattani et al., 2014). 
The possibility of modifying milk fat content and fatty acids profile through cow nutrition may enable producers to respond to human health recommendations in the context of a balanced diet (Woods and Fearon, 2009; Poulsen et al., 2012; Shingfield et al., 2013). For this purpose, particular attention has been paid to the presence in ruminant products of some PUFA, the n6-to-n3 fatty acid ratio, and CLA. These latter are produced by rumen biohydrogenation of linoleic acid and by the metabolism of various tissues, including the mammary gland, adipose tissue, and muscle (Lock and Bauman, 2004). Dietary CLA are reported to promote beneficial health-related effects on body composition and also show anticarcinogenic, antiatherogenic, antidiabetogenic, and immune-modulating properties (Rainer and Heiss, 2004). Likewise, feed ingredients rich in linolenic acid were found to be effective in reducing the n6-to-n3 ratio toward values $<5$, which are considered to be safe for the consumer (Danneberger et al., 2013).

Genetic variability has been found to influence the presence of some fatty acids, mainly those originating from de novo mammary fatty acid synthesis (e.g., Stoop et al., 2008; Mele et al., 2009; Krag et al., 2013), and between-breed differences have been observed in milk fatty acid profiles (White et al., 2001; Kelsey et al., 2003; Maurice-Van Eijndhoven et al., 2011). Furthermore, high-level genetic correlations have been observed among fatty acid that share similar metabolic production pathways (Soyeurt et al., 2007; Stoop et al., 2008).

Due to the high cost of GC analysis, most previous studies have focused on a limited number of fatty acid in a small number of animals. More recently, researchers have investigated the use of Fourier-transform infrared (FTIR) spectrometry to inexpensively predict the fatty acid concentration of bovine milk (Soyeurt et al., 2006; De Marchi et al., 2011; Bastin et al., 2013). The existing studies have considered various breeds, but examined relatively few (6-11) fatty acids. Gas chromatography has some major advantages over FTIR, including higher precision and accuracy in measuring a large number of fatty acids, even those present at low concentrations in milk fat (Rutten et al., 2010). Few studies have used GC to examine how genetic and herd factors affect the milk profile of 23 to 26 fatty acid traits: namely Stoop et al. (2008), Garnsworthy et al. (2010), and Heck et al. (2012). Only Bilal et al. (2014) reported data on 33 fatty acids and also evaluated all the genetic parameters based on GC analysis for the Holstein Friesian breed. In Brown Swiss cows, the genetic parameters of only 4 fatty acid categories (i.e., SFA, unsaturated fatty acids, MUFA, and PUFA predicted by FTIR and expressed as the relative content in a kilogram of milk) were previously estimated
(Tullo et al., 2014). Few studies are available to evaluate the genetic, herd and residual correlations among different fatty acids (Duchemin et al., 2013). A deeper knowledge about the genetic or the environmental relationships among fatty acid provides useful information to identify the best strategies for manipulating the milk fatty acid profile.

The aims of this study were (1) to use a large GCbased data set to characterize the profile of 47 individual fatty acids, 13 fatty acid groups, and 5 calculated desaturation indices in Brown Swiss cows; (2) to estimate the genetic variation and heritability of these traits and assess their statistical relevance using the Bayes factor (BF) test; (3) to quantify the between herd-date variation; and (4) to infer the additive genetic, herd-date, and residual relationships among all fatty acids and fatty acid categories.

\section{MATERIALS AND METHODS}

\section{Animals and Milk Sampling}

Milk samples were collected from 1,158 Brown Swiss cows from 85 herds (a maximum of 15 cows per herd) located in the Alpine province of Trento (Italy). Milk samples were collected once per cow during the evening milking. Each farm was sampled once. The milk samples (no preservative was added) were immediately refrigerated at $4^{\circ} \mathrm{C}$ and transferred to the Cheese-Making Laboratory of the Department of Agronomy, Food, Natural Resources, Animals and Environment of the University of Padova (Legnaro, Padova, Italy). Data on the cows and herds were provided by the Superbrown Consortium of Bolzano and Trento (Italy), and pedigree information was supplied by the Italian Brown Swiss Cattle Breeders Association (ANARB, Verona, Italy). We included cows with phenotypic records available for the investigated traits and all known ancestors. Each sampled cow had known ancestors for at least 4 generations and the pedigree file included 8,845 animals.

\section{GC Analysis}

Fatty acid methyl esters were prepared by the direct extraction and alkali catalyzed trans-methylation procedure previously described by Feng et al. (2004). Briefly, each milk sample was centrifuged at 5,000 $\times g$ for $30 \mathrm{~min}$ at $4^{\circ} \mathrm{C}$ to facilitate the separation of the fat at the surface. Thirty milligrams of fat was collected in a fresh amber vial, mixed with $3 \mathrm{~mL}$ of hexane and 0.3 $\mathrm{mL}$ of $2 M$ methanolic solution of $\mathrm{KOH}$, and the mixture was incubated for $5 \mathrm{~min}$ at room temperature after the addition of $0.25 \mathrm{mg}$ of $\mathrm{NaHSO}_{3} \times \mathrm{H}_{2} \mathrm{O}$. The samples were then centrifuged at $3,000 \times g$ for 3 min at $4^{\circ} \mathrm{C}$ and 
the upper layer was collected for GC analysis. The fatty acid composition was determined using a ThermoQuest gas chromatograph (ThermoElectron Corp., Waltham, MA) equipped with a flame-ionization detector and a high polar fused-silica capillary column (Chrompack CP-Sil88 Varian, Middelburg, the Netherlands; 100 m, $0.25 \mathrm{~mm}$ i.d.; film thickness $0.20 \mu \mathrm{m})$. Helium was used as the carrier gas at a flow rate of $1 \mathrm{~mL} / \mathrm{min}$. A split/ splitless injector was used with a split ratio of 1:80. An aliquot of the sample was injected under the following GC conditions: the initial oven temperature $\left(60^{\circ} \mathrm{C}\right)$ was held for $1 \mathrm{~min}$, increased to $173^{\circ} \mathrm{C}$ at a rate of $2^{\circ} \mathrm{C} / \mathrm{min}$, held at $173^{\circ} \mathrm{C}$ for $30 \mathrm{~min}$, increased to $185^{\circ} \mathrm{C}$ at $1^{\circ} \mathrm{C} /$ min, and held at $185^{\circ} \mathrm{C}$ for $5 \mathrm{~min}$, increased to $220^{\circ} \mathrm{C}$ at a rate of $3^{\circ} \mathrm{C} / \mathrm{min}$, and finally held at $220^{\circ} \mathrm{C}$ for 19 min. The injector temperature was set to $270^{\circ} \mathrm{C}$ and the detector temperature was set to $300^{\circ} \mathrm{C}$.

Individual FAME were identified by comparison to a standard mixture (52 Component FAME Mix, GLC674; Nu-Chek Prep Inc., Elysian, MN). The isomers of C18:1 were identified with reference to commercial pure standards (47199, 46903, 46905; Supelco, Bellefonte PA) and published isomeric profiles (Kramer et al., 2008). A reference standard butter (BCR 164; Commission of the European Communities, Community Bureau of Reference, Brussels, Belgium) was used to estimate correction factors for the short-chain fatty acids, as previously described by Mele et al. (2008). Inter- and intra-assay coefficients of variation were also calculated using the above reported reference standard butter and the detection limit of the analysis was $0.001 \%$ above that of the total fatty acid amount. The milk fatty acid composition was expressed as grams per $100 \mathrm{~g}$ of total fatty acids.

\section{Statistical Analysis}

Nongenetic Effects. Nongenetic effects, which were included in the mixed models used to estimate the genetic parameters for fatty acids, were identified through preliminary analysis based on the GLM procedure (SAS Institute Inc., Cary, NC). For all traits, the model accounted for the effects of herd-date (85 levels), DIM (class $1=<60 \mathrm{~d}$; class $2=60-120 \mathrm{~d}$; class $3=$ 121-180 d; class $4=181-240 \mathrm{~d}$; class $5=241-300 \mathrm{~d}$; and class $6=>300 \mathrm{~d}$ ), and parity ( 1 to 4 or more). All these effects were found to be important sources of variation $(P<0.05)$.

Univariate Models for Testing the Hypothesis of Additive Genetic Determination. The genetic parameters of fatty acids, fatty acid categories, and indices (y) were investigated by analyzing data under the following hierarchical model:

$$
\mathbf{y}=\mathbf{X b}+\mathbf{Z}_{1} \mathbf{h}+\mathbf{Z}_{2} \mathbf{a}+\mathbf{e},
$$

where $\mathbf{y}$ was the vector of phenotypic records with dimension $\mathrm{n} ; \mathbf{X}, \mathbf{Z}_{1}$, and $\mathbf{Z}_{2}$ were appropriate incidence matrices for the systematic effects (b), herd-date effects (h), and polygenic additive genetic effects (a), respectively; and e was the vector of residual effects. More specifically, $\mathbf{b}$ included the nongenetic effects of DIM and parity.

All models were analyzed under a standard Bayesian approach. The joint distribution of the parameters in a given model was proportional to:

$$
\begin{aligned}
& p\left(\mathbf{b}, \mathbf{h}, \mathbf{a}, \sigma_{e}^{2}, \sigma_{h}^{2}, \sigma_{a}^{2} \mid \mathbf{y}\right) \propto p\left(\mathbf{y} \mid \mathbf{b}, \mathbf{h}, \mathbf{a}, \sigma_{e}^{2}\right) p\left(\sigma_{e}^{2}\right) p(\mathbf{b}) \times \\
& p\left(\mathbf{h} \mid \sigma_{h}^{2}\right) p\left(\sigma_{h}^{2}\right) p\left(\mathbf{a} \mid \mathbf{A}, \sigma_{a}^{2}\right) p\left(\sigma_{a}^{2}\right),
\end{aligned}
$$

where $\mathbf{A}$ was the numerator relationship matrix between individuals (Wright, 1922) and $\sigma_{e}^{2}, \sigma_{h}^{2}$, and $\sigma_{a}^{2}$ were the residual, herd-date, and additive genetic variances, respectively. The a priori distributions of $\mathbf{h}$ and a were assumed to be multivariate normal, as follows:

$$
\begin{gathered}
p\left(\mathbf{h} \mid \sigma_{h}^{2}\right) \sim N\left(0, \mathbf{I} \sigma_{h}^{2}\right) \\
p\left(\mathbf{a} \mid \sigma_{a}^{2}\right) \sim N\left(0, \mathbf{A} \sigma_{a}^{2}\right),
\end{gathered}
$$

where $\mathbf{I}$ was an identity matrix with dimensions equal to the number of elements in $\mathbf{h}$. The priors for $\mathbf{b}$ and the variance components were assumed to be flat.

The univariate model was employed to test for the additive genetic determination of each trait. The BF (Kass and Raftery, 1995; García-Cortés et al., 2001; Casellas et al., 2010) was computed as a pair-wise comparison by calculating the ratio between the posterior probabilities of 2 competing models and taking any positive value between 0 and infinity. In this case, a linear mixed model with additive polygenic effects (the numerator model) was compared with a corresponding model without the additive polygenic effects (the denominator model); $\mathrm{BF}>1$ favored the numerator model, whereas $\mathrm{BF}<1$ favored the denominator model. The BF results are discussed within the context of the discrete scale of evidences described by Jeffreys (1984), which objectively classifies the BF according to 6 different levels of evidence for the numerator model, namely denominator model supported, not worth more than a bare mention, substantial evidence, strong evidence, very strong evidence, and decisive evidence. Henceforth, this terminology will be systematically used when referring to the $\mathrm{BF}$.

Bivariate Models for Estimating BetweenTrait Correlations. To estimate genetic correlations 
between fatty acid variables, we conducted a set of bivariate analyses that implemented model 1 in its multivariate version. In this case, the involved traits were assumed to jointly follow a multivariate normal distribution along with the additive genetic, herd-date, and residual effects. For these effects, the corresponding prior distributions were:

$$
\begin{aligned}
& \mathbf{a} \mid \mathbf{G}_{0}, \mathbf{A} \sim \operatorname{MVN}\left(0, \mathbf{G}_{0} \otimes \mathbf{A}\right), \\
& \mathbf{h} \mid \mathbf{H}_{0} \sim N\left(0, \mathbf{H}_{0} \otimes \mathbf{I}_{n}\right), \text { and } \\
& \mathbf{e} \mid \mathbf{R}_{0} \sim N\left(0, \mathbf{R}_{0} \otimes \mathbf{I}_{m}\right),
\end{aligned}
$$

where $\mathbf{G}_{0}, \mathbf{H}_{0}$, and $\mathbf{R}_{0}$ were the corresponding variancecovariance matrices between the involved traits, respectively, and $\mathbf{a}, \mathbf{h}$, and $\mathbf{e}$ were vectors of dimension equal to the number of animals in the pedigree $(n$ and $m)$ times the number of traits considered.

Gibbs Sampler. Marginal posterior distributions of unknown parameters were estimated by performing numerical integration using the Gibbs sampler (Gelfand and Smith, 1990), which was employed to obtain auto-correlated samples from the joint posterior distributions and, subsequently, from the marginal posterior distributions of all unknowns in the model. The lengths of the chain and the burn-in period were assessed by visual inspection of trace plots, and by the diagnostic tests described by Geweke (1992) and Gelman and Rubin (1992). After a preliminary run, we decided to construct a single chain consisting of 850,000 iterations and discard the first 50,000 iterations as a very conservative burn-in. We subsequently retained 1 of every 200 successive samples to store draws that were more loosely correlated. Thus, 4,000 samples were used to determine the posterior distributions of the unknown parameters. The lower and upper bounds of the highest $95 \%$ probability density regions for the parameters of concern were obtained from the estimated marginal densities. The posterior median was used as the point estimate for all parameters. Auto-correlations between samples and estimates of the Monte Carlo standard error (Geyer, 1992) were also calculated. The analyses were implemented in a FORTRAN90 program.

Heritability was computed as

$$
\mathrm{h}^{2}=\frac{\sigma_{a}^{2}}{\sigma_{a}^{2}+\sigma_{h}^{2}+\sigma_{e}^{2}} .
$$

The proportion of the total variance caused by herddate $\left(\mathrm{h}_{\text {herd }}\right)$ was computed as

$$
\mathrm{h}_{\text {herd }}=\frac{\sigma_{a}^{2}}{\sigma_{a}^{2}+\sigma_{h}^{2}+\sigma_{e}^{2}} .
$$

Here, $\sigma_{a}^{2}, \sigma_{h}^{2}$, and $\sigma_{e}^{2}$ were the additive genetic, herddate, and residual variances, respectively. The additive genetic correlations $\left(r_{a}\right)$ were computed as

$$
r_{a}=\frac{\sigma_{a 1, a 2}}{\sigma_{a 1} \times \sigma_{a 2}},
$$

where $\sigma_{a 1, a 2}$ was the additive genetic covariance between traits 1 and 2, and $\sigma_{a 1}$ and $\sigma_{a 2}$ were the additive genetic standard deviations for traits 1 and 2, respectively. The herd-date correlations $\left(r_{h}\right)$ were computed as

$$
r_{h}=\frac{\sigma_{h 1, h 2}}{\sigma_{h 1} \times \sigma_{h 2}},
$$

where $\sigma_{h 1, h 2}$ was the herd-date covariance between traits 1 and 2 , and $\sigma_{h 1}$ and $\sigma_{h 2}$ were the herd-date standard deviations for traits 1 and 2 , respectively. The residual correlations $\left(r_{e}\right)$ were computed as

$$
r_{e}=\frac{\sigma_{e 1, e 2}}{\sigma_{e 1} \times \sigma_{e 2}},
$$

where $\sigma_{e 1}$ was the residual covariance between traits 1 and 2 , and $\sigma_{e 1}$ and $\sigma_{e 2}$ were the residual standard deviations for traits 1 and 2 , respectively. For clustering purposes, the additive genetic, herd-date, and residual correlation matrices were subsequently fed to the $\mathrm{R}$ function, "hclust" (Maechler et al., 2012), which uses the complete linkage method for hierarchical clustering, as detailed in Maechler et al. (2012).

\section{RESULTS}

\section{Descriptive Statistics for Milk Production Traits and Fatty Acid Composition}

Milk yield averaged $24.4 \mathrm{~kg} / \mathrm{d}$ and the milk fat content averaged $4.23 \%$ (Table 1 ). The phenotypic variation for milk yield was high $(\mathrm{CV}=33 \%)$ and almost double that observed for the milk fat content $(\mathrm{CV}=$ $17 \%$ ). The GC analysis allowed us to identify and to determine 47 fatty acids: 22 SFA, 13 MUFA, and 12 PUFA. Both $\mathrm{C} 16: 0$ and $\mathrm{C} 18: 1$ cis-9 were the major fatty acids found in milk, followed by C14:0 and C18:0. The least represented fatty acids were C18:1 trans- 4 , C22:4 cis-7,cis-10,cis-13,cis-16, C18:3 cis-9,trans11,cis-15, and C24:0. We observed large variabilities among the individual fatty acids, with coefficients of variation ranging from $13 \%(\mathrm{C} 14: 0)$ to as high as $80 \%$ (C18:2 trans-11,cis-15). 
Table 1. Descriptive statistics for milk production traits and individual fatty acids $(\mathrm{FA} ; \mathrm{n}=1,158)$

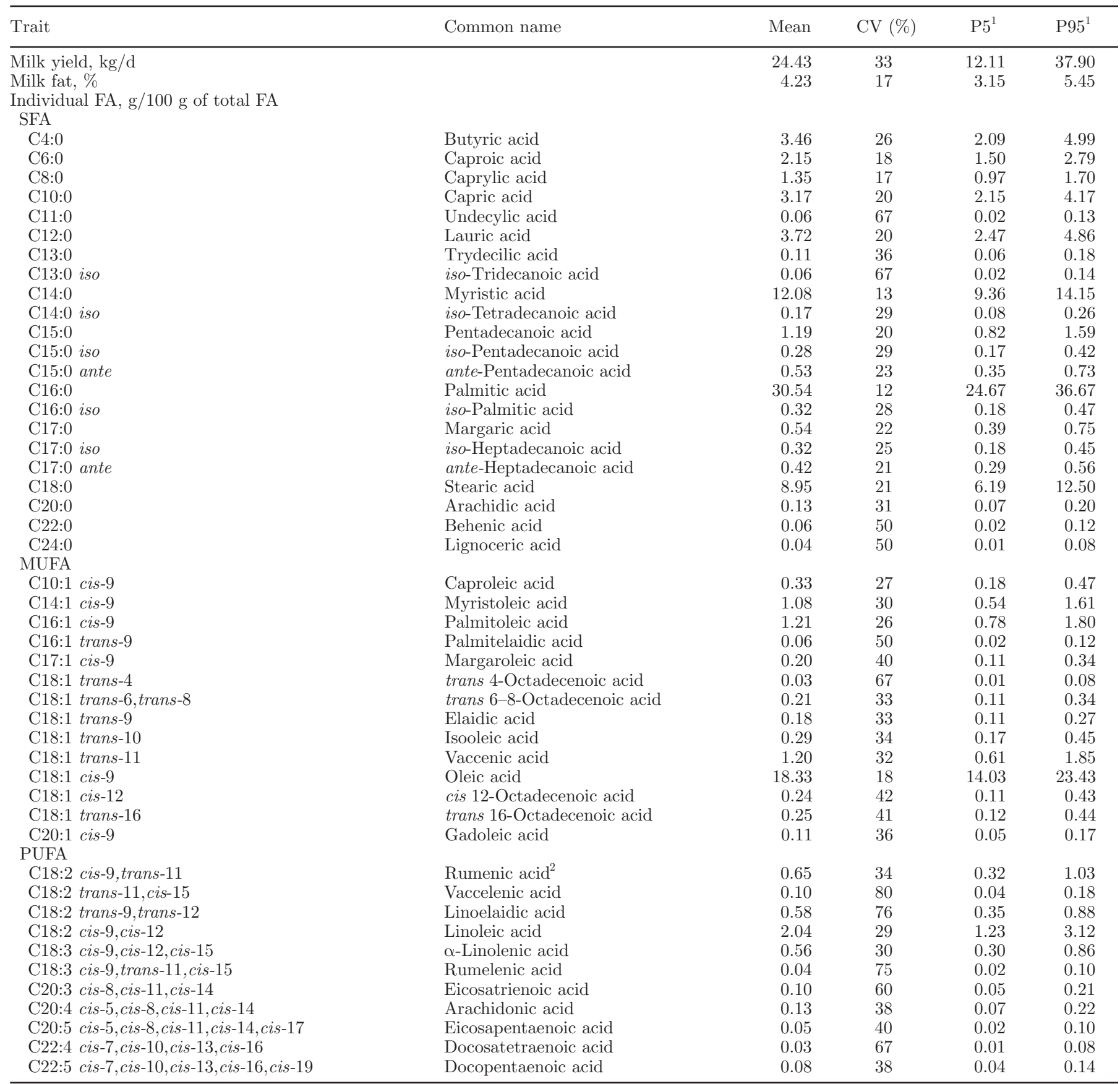

${ }^{1} \mathrm{P} 5=5$ th percentile; P95 $=95$ th percentile.

${ }^{2}$ Tested CLA included C18:2 cis-9,trans-11 (rumenic acid; RA) and C18:2 trans-7,cis-9. The term RA is used herein to indicate the sum of the 2 isomers.

The major fatty acid categories were defined according to the desaturation status for SFA and based on the carbon chain length for medium-chain (MCFA) and long-chain fatty acids (LCFA; Table 2). Descriptive statistics for the contents of the various fatty acids classified on the desaturation indices showed that the C18 index had the highest mean content value $(67.22 \%)$, followed by the CLA index (34.98\%). The short-chain desaturation index (for C10) and the MCFA desaturation indices (for $\mathrm{C} 14$ and $\mathrm{C} 16$ ) were small. For the selected fatty acid categories and the desaturation indices, the variabilities were smaller than those observed for individual fatty acids, and the coefficients of variation were 6 to $25 \%$. 
Table 2. Descriptive statistics for groups of fatty acids and unsaturation indices $(\mathrm{n}=1,158)$

\begin{tabular}{lrrrr}
\hline Trait & Mean & CV $(\%)$ & P5 & P95 $^{1}$ \\
\hline Group of fatty acids, g/100 g of fatty acids ${ }^{2}$ & & & & \\
SFA & 69.63 & 6 & 61.98 & 75.50 \\
MUFA & 24.24 & 14 & 19.52 & 29.88 \\
PUFA & 3.78 & 21 & 2.66 & 5.13 \\
SCFA & 10.52 & 16 & 7.68 & 13.25 \\
MCFA & 52.81 & 10 & 43.11 & 60.79 \\
LCFA & 34.38 & 15 & 26.94 & 43.45 \\
BCFA & 2.08 & 20 & 1.47 & 2.78 \\
OCFA & 1.89 & 17 & 1.44 & 2.44 \\
n-6 fatty acids & 2.31 & 28 & 1.43 & 3.50 \\
n-3 fatty acids & 0.69 & 29 & 0.40 & 1.04 \\
n-6/n-3 & 3.52 & 33 & 1.95 & 5.70 \\
trans fatty acids & 2.22 & 24 & 1.42 & 3.07 \\
trans fatty acids C18:1 & 2.16 & 24 & 1.37 & 3.00 \\
Unsaturation index, $\%$ & & & & \\
C10:1/(C10:0+C10:1) & 9.54 & 21 & 0.06 & 0.13 \\
C14:1/(C14:0+C14:1) & 8.16 & 25 & 0.05 & 0.12 \\
C16:1/(C16:0+C16:1) & 3.83 & 23 & 0.03 & 0.05 \\
C18:1/(C18:0+C18:1) & 67.22 & 6 & 0.60 & 0.73 \\
RA/(RA+VA) & 34.98 & 16 & 0.26 & 0.44 \\
\hline
\end{tabular}

${ }^{1} \mathrm{P} 5=5$ th percentile; P95 $=$ 95th percentile.

${ }^{2} \mathrm{SCFA}=$ short-chain fatty acids; MCFA = medium-chain fatty acids; LCFA = long-chain fatty acids; BCFA $=$ branched-chain fatty acids; OCFA = odd-chain fatty acids. SCFA included the C4:0, C6:0, C8:0, and C10:0 fatty acids; MCFA included all linear fatty acids from C11:0 to C16:1; LCFA included all linear fatty acids from C17:0 to C24:0; trans fatty acids included all trans fatty acids; trans fatty acids C18:1 included all trans isomers of C18:1.

${ }^{3} \mathrm{RA}=$ rumenic acid; $\mathrm{VA}=$ vaccenic acid.

\section{Genetic Determinism and BF}

The milk yield and milk fat content had $\mathrm{BF}>10$, supporting the existence of additive genetic variation (Table 3). Some individual fatty acids, including C14:1 cis-9, C16:0, C12:0, C18:0, C16:1 cis-9, and C10:0, had high BF ranging from 8 to 71 . These fatty acids also had moderate-to-high estimated heritabilities (on the order of 0.201 to 0.360 ). Small genetic effects (in terms of $\mathrm{BF}$ and heritability) were observed for the other fatty acids, such as C4:0, C6:0, vaccenic acid (VA), and rumenic acid (RA).

With respect to the fatty acid categories and desaturation indices (Table 4), the greatest BF and heritability values were observed for the $\mathrm{C} 14$ index $\left(\mathrm{BF}=76.06, \mathrm{~h}^{2}\right.$ $=0.438)$. The C18 index and the SFA, PUFA, MCFA, and trans fatty acids categories also had high $\mathrm{BF}(>10)$ and heritability values $(>0.10)$. In contrast, no genetic effect was observed for $\mathrm{RA}$-to- $(\mathrm{RA}+\mathrm{VA})$ ratio $(\mathrm{BF}=$ $\left.0.055, \mathrm{~h}^{2}=0.098\right)$.

\section{The Contribution of Herd-Date Effect on the Phenotypic Variation}

The existence of relatively high herd-date contribution to the total phenotypic variance was observed for the milk yield and milk fat content $(0.45$ and 0.42 , respectively; Table 3). Among the individual fatty acids, a similar finding (with proportions varying from 0.41 to 0.61) was obtained for VA, RA, C4:0, C6:0, C16:0, and all of the branched-chain fatty acids (BCFA). Overall, the PUFA, the trans fatty acids, and trans C18:1 showed herd-date contributions ranging from 0.54 to 0.61 (Table 4). In contrast, the desaturation indices yielded herd-date contributions that were much lower than the heritability estimates, with the exception of the RA-to-(RA+VA) ratio, for which the herd-date effect accounted for $24 \%$ of the total phenotypic variance.

\section{Genetic Correlations Among Groups of Fatty Acids}

The additive genetic correlations between the SFA and almost all of the other fatty acids groups were negative, with the exception of the MCFA (0.69) (Table 5). Trans C18:1 showed correlations higher than 0.61 with the MUFA, LCFA, BCFA, and trans fatty acids, and the correlation with the PUFA was 0.48. No relevant additive genetic correlation was found between production traits (milk yield and milk fat content) and any individual fatty acid.

\section{Genetic, Herd-Date, and Residual Correlations Among the Detailed Milk Fatty Acid Profiles}

The additive genetic correlations among the individual fatty acids are presented in Figure 1a. The de novo 
Table 3. Estimates of Bayes factor, genetic variance $\left(\sigma_{a}^{2}\right)$, herd-date variance $\left(\sigma_{h}^{2}\right)$, residual variance $\left(\sigma_{e}^{2}\right)$, heritability $\left(h^{2}\right)$, and herd-date variance as proportion of total variance $\left(\mathrm{h}_{\text {herd }}\right)$ for milk production traits and individual fatty acids $(\mathrm{n}=1,158)$

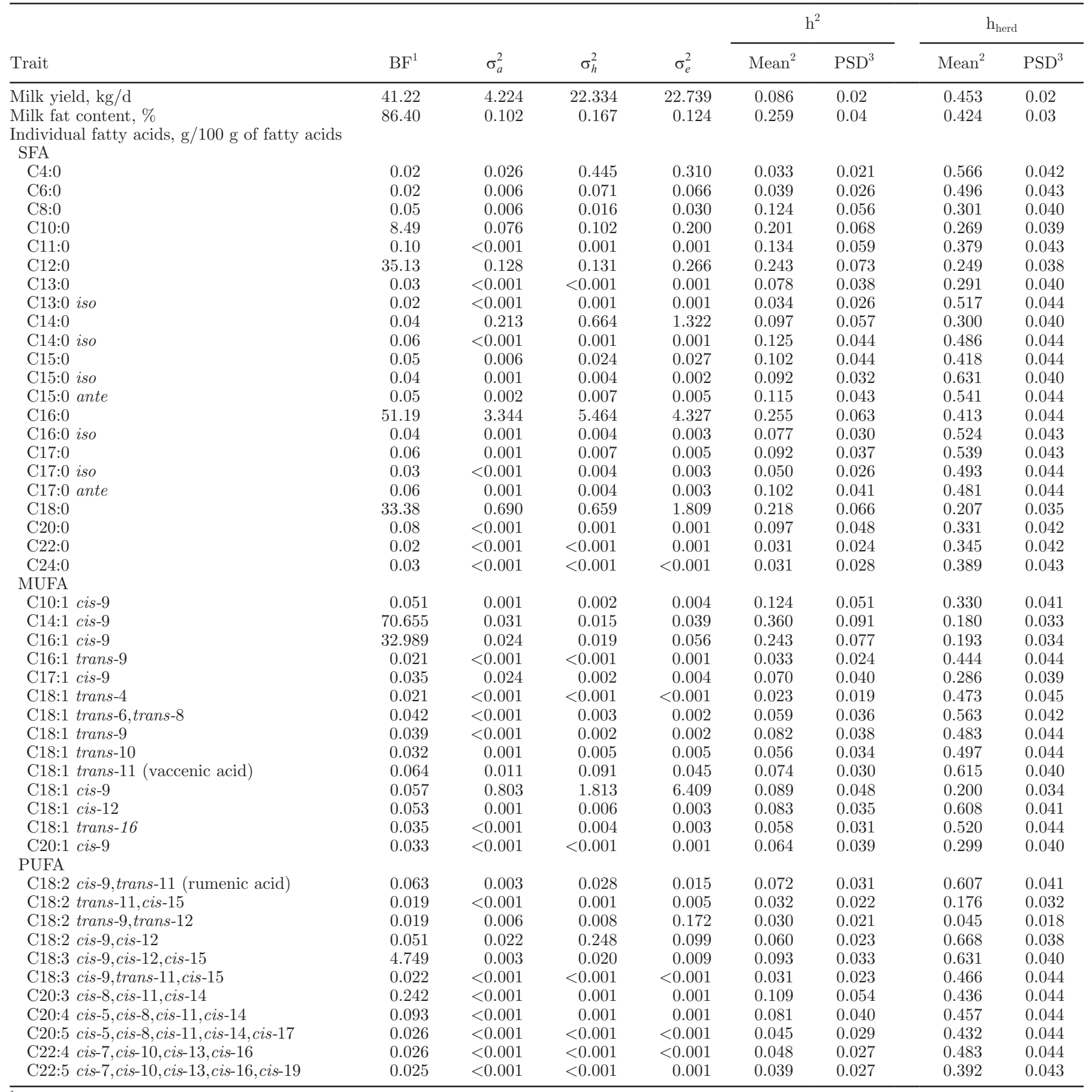

${ }^{1} \mathrm{BF}=$ Bayes factor of the model with additive polygenic effects (numerator model) against the same model without additive polygenic effects (denominator model), where $>1 \mathrm{BF}$ favored the numerator model and $<1 \mathrm{BF}$ favored the denominator model; $\mathrm{h}^{2}=\sigma_{a}^{2} / \sigma_{a}^{2}+\sigma_{h}^{2}+\sigma_{e}^{2}$; $\mathrm{h}_{\text {herd }}=\sigma_{h}^{2} / \sigma_{a}^{2}+\sigma_{h}^{2}+\sigma_{e}^{2}$.

${ }^{2}$ Mean of the marginal posterior density of the parameter.

${ }^{3} \mathrm{PSD}=$ posterior standard deviation. 
Table 4. Estimates of Bayes factor, genetic variance $\left(\sigma_{a}^{2}\right)$, herd-date variance $\left(\sigma_{h}^{2}\right)$, residual variance $\left(\sigma_{e}^{2}\right)$, heritability $\left(h^{2}\right)$, and herd-date variance as proportion of total variance $\left(\mathrm{h}_{\mathrm{herd}}\right)$ for groups of fatty acids and unsaturation index $(\mathrm{n}=1,158)$

\begin{tabular}{|c|c|c|c|c|c|c|c|c|}
\hline Trait & $\mathrm{BF}^{1}$ & $\sigma_{a}^{2}$ & $\sigma_{h}^{2}$ & $\sigma_{e}^{2}$ & \multicolumn{2}{|c|}{$\mathrm{h}^{2}$} & \multicolumn{2}{|c|}{$\mathrm{h}_{\text {herd }}$} \\
\hline \multicolumn{9}{|c|}{ Group of fatty acids, ${ }^{4} \mathrm{~g} / 100 \mathrm{~g}$ of fatty acids } \\
\hline MUFA & 4.394 & 1.390 & 2.230 & 6.874 & 0.132 & 0.061 & 0.211 & 0.035 \\
\hline PUFA & 17.196 & 0.068 & 0.393 & 0.178 & 0.107 & 0.037 & 0.611 & 0.041 \\
\hline SCFA & 0.043 & 0.151 & 1.349 & 1.319 & 0.054 & 0.031 & 0.475 & 0.044 \\
\hline BCFA & 1.314 & 0.014 & 0.099 & 0.052 & 0.083 & 0.032 & 0.598 & 0.041 \\
\hline OCFA & 1.645 & 0.013 & 0.049 & 0.043 & 0.121 & 0.044 & 0.463 & 0.043 \\
\hline n- 6 fatty acid & 0.054 & 0.029 & 0.298 & 0.112 & 0.066 & 0.025 & 0.676 & 0.036 \\
\hline n-3 fatty acid & 1.567 & 0.003 & 0.026 & 0.011 & 0.085 & 0.032 & 0.634 & 0.039 \\
\hline$n-6 / n-3$ & 0.025 & 0.051 & 1.135 & 0.294 & 0.034 & 0.016 & 0.763 & 0.029 \\
\hline trans fatty acid & 24.362 & 0.031 & 0.161 & 0.098 & 0.107 & 0.039 & 0.552 & 0.043 \\
\hline trans fatty acid C18:1 & 22.123 & 0.030 & 0.151 & 0.094 & 0.111 & 0.040 & 0.543 & 0.043 \\
\hline $\mathrm{RA} /(\mathrm{RA}+\mathrm{VA})^{5}$ & 0.055 & 2.6699 & 6.6052 & 18.0357 & 0.098 & 0.053 & 0.240 & 0.037 \\
\hline
\end{tabular}

${ }^{1} \mathrm{BF}=$ Bayes factor of the model with additive polygenic effects (numerator model) against the same model without additive polygenic effects (denominator model), where greater-than-1 BF favored the numerator model and less-than-1 BF favored the denominator model; $\mathrm{h}^{2}=\sigma_{a}^{2} / \sigma_{a}^{2}+\sigma_{h}^{2}+\sigma_{e}^{2} ; \mathrm{h}_{\text {herd }}=\sigma_{h}^{2} / \sigma_{a}^{2}+\sigma_{h}^{2}+\sigma_{e}^{2}$.

${ }^{2}$ Mean of the marginal posterior density of the parameter.

${ }^{3} \mathrm{PSD}=$ posterior standard deviation.

${ }^{4} \mathrm{SCFA}=$ short-chain fatty acids; MCFA = medium-chain fatty acids; LCFA = long-chain fatty acids; BCFA = branched-chain fatty acids; OCFA = odd-chain fatty acids; SCFA included the C4:0, C6:0, C8:0 and C10:0 fatty acids: MCFA included all linear fatty acids from C11:0 to C16:1; LCFA included all linear fatty acids from C17:0 to C24:0; trans fatty acids included all trans fatty acids; trans fatty acids C18:1 included all trans isomers of C18:1.

${ }^{5} \mathrm{RA}=$ rumenic acid; VA = vaccenic acid.

synthesized fatty acids (e.g., C6:0, C8:0, C10:0, C12:0, and $\mathrm{C} 14: 0)$ showed high positive genetic correlations between each other. This was further confirmed by the general tight clustering observed between fatty acids with chains differing by only 2 carbons atoms (Figure 2a), although C4:0, C15:0, C16:0, and C17:0 clustered separately. The $\mathrm{C} 16: 0$ showed negative genetic correlations with $\mathrm{C} 6: 0, \mathrm{C} 8: 0, \mathrm{C} 10: 0, \mathrm{C} 15$ iso, $\mathrm{C} 15: 0$ anteiso, and many fatty acids of the C18:1 series. However, it showed positive relationships with $\mathrm{C} 18: 3$ and other

Table 5. Additive genetic correlations between groups of fatty acids $(\mathrm{n}=1,158)^{1}$

\begin{tabular}{|c|c|c|c|c|c|c|c|c|c|}
\hline Item $^{2}$ & SFA & MUFA & PUFA & SCFA & MCFA & LCFA & BCFA & $\begin{array}{l}\text { trans fatty } \\
\text { acids }\end{array}$ & $\begin{array}{l}\text { trans fatty } \\
\text { acids C18:1 }\end{array}$ \\
\hline $\begin{array}{l}\text { SFA } \\
\text { MUFA } \\
\text { PUFA } \\
\text { SCFA } \\
\text { MCFA } \\
\text { LCFA } \\
\text { BCFA } \\
\text { trans fatty acids }\end{array}$ & & -0.89 & $\begin{array}{r}-0.72 \\
0.57\end{array}$ & $\begin{array}{r}0.17 \\
-0.17 \\
-0.07\end{array}$ & $\begin{array}{r}\mathbf{0 . 6 9} \\
-\mathbf{0 . 7 6} \\
-0.38 \\
-0.31\end{array}$ & $\begin{array}{r}-\mathbf{0 . 6 3} \\
\mathbf{0 . 8 4} \\
0.38 \\
0.23 \\
-\mathbf{0 . 9 1}\end{array}$ & $\begin{array}{r}-0.22 \\
0.43 \\
0.22 \\
0.12 \\
-0.59 \\
\mathbf{0 . 7 0}\end{array}$ & $\begin{array}{r}-0.71 \\
\mathbf{0 . 7 7} \\
0.50 \\
-0.04 \\
-\mathbf{0 . 7 8} \\
\mathbf{0 . 8 5} \\
\mathbf{0 . 5 9}\end{array}$ & $\begin{array}{r}-\mathbf{0 . 7 1} \\
\mathbf{0 . 7 6} \\
0.48 \\
-0.05 \\
-\mathbf{0 . 7 9} \\
\mathbf{0 . 8 5} \\
\mathbf{0 . 6 1} \\
\mathbf{1 . 0 0}\end{array}$ \\
\hline
\end{tabular}

${ }^{1}$ Mean of the marginal posterior density of the additive genetic correlation; bold indicates additive genetic correlations with $\geq 90 \%$ of posterior probability accumulated above 0 (positive estimates) or below 0 (negative estimates).

${ }^{2} \mathrm{SCFA}=$ short-chain fatty acids; MCFA = medium-chain fatty acids; LCFA = long-chain fatty acids; BCFA = branched-chain fatty acids; OCFA = odd-chain fatty acids. SCFA included the C4:0, C6:0, C8:0 and C10:0 fatty acids; MCFA included all linear fatty acids from C11:0 to C16:1; LCFA included all linear fatty acids from C17:0 to C24:0; trans fatty acids included all trans fatty acids; trans fatty acids C18:1 included all trans isomers of C18:1. 
PUFA with $>18$ carbon chains, and it clustered tightly with C11:0. A negative genetic correlation was observed between $\mathrm{C} 16: 0$ and C18:0 (-0.54). Positive additive genetic correlations were observed between $\mathrm{C} 18: 0$ and C16:0 iso, C20:0, C22:0, and C18:1 trans-11 (VA; 0.69). The C18:1 trans-11 showed positive genetic relationships with many members of the C18:1 fatty acid group and with RA (0.65), even though the latter co-eluted with $\mathrm{C} 18: 2$ trans-7,cis-9. The additive genetic correlations among the fatty acids of the C18 group were generally positive, with some exceptions. For example, we observed negative correlations between C18:0 and C18:2 cis-9,cis-12 (linoleic acid; -0.47), C18:0 and C18:3 cis-9,trans-11,cis-15 (-0.37), C18:1 trans-11 (VA) and C18:2 trans-9,trans-12 (-0.39), C18:1c9 and C18:3 cis-9,trans-11,cis-15 (-0.45), and C18:1 trans-6-8 and $\mathrm{C} 18: 3$ cis-9,trans-11, cis-15 (-0.35). A positive ad- ditive genetic correlation was observed between C18:0 and C20:0 (0.75), and this was further confirmed by their tight clustering.

The herd-date correlations observed among the fatty acids are depicted in Figure 1b. Within the group of de novo synthesized fatty acids, C4:0 and C6:0 (0.89) were positively correlated and they clustered together (Figure 2b). High herd-date correlations were also observed between C10:0 and C12:0 (0.89), C11:0 and C13:0 (0.94), and C12:0 and C14:0 (0.58). Consistent with our findings for the genetic component, however, the correlation between C16:0 and C18:0 was negative $(-0.66)$. Within the $\mathrm{C} 18$ fatty acids group, VA and RA showed a strong positive correlation (0.91) and tight clustering. Unlike our findings for the genetic component, however, a weak herd-date correlation was observed between C18:0 and VA (0.25). Overall, the

\section{[a] Additive genetic}

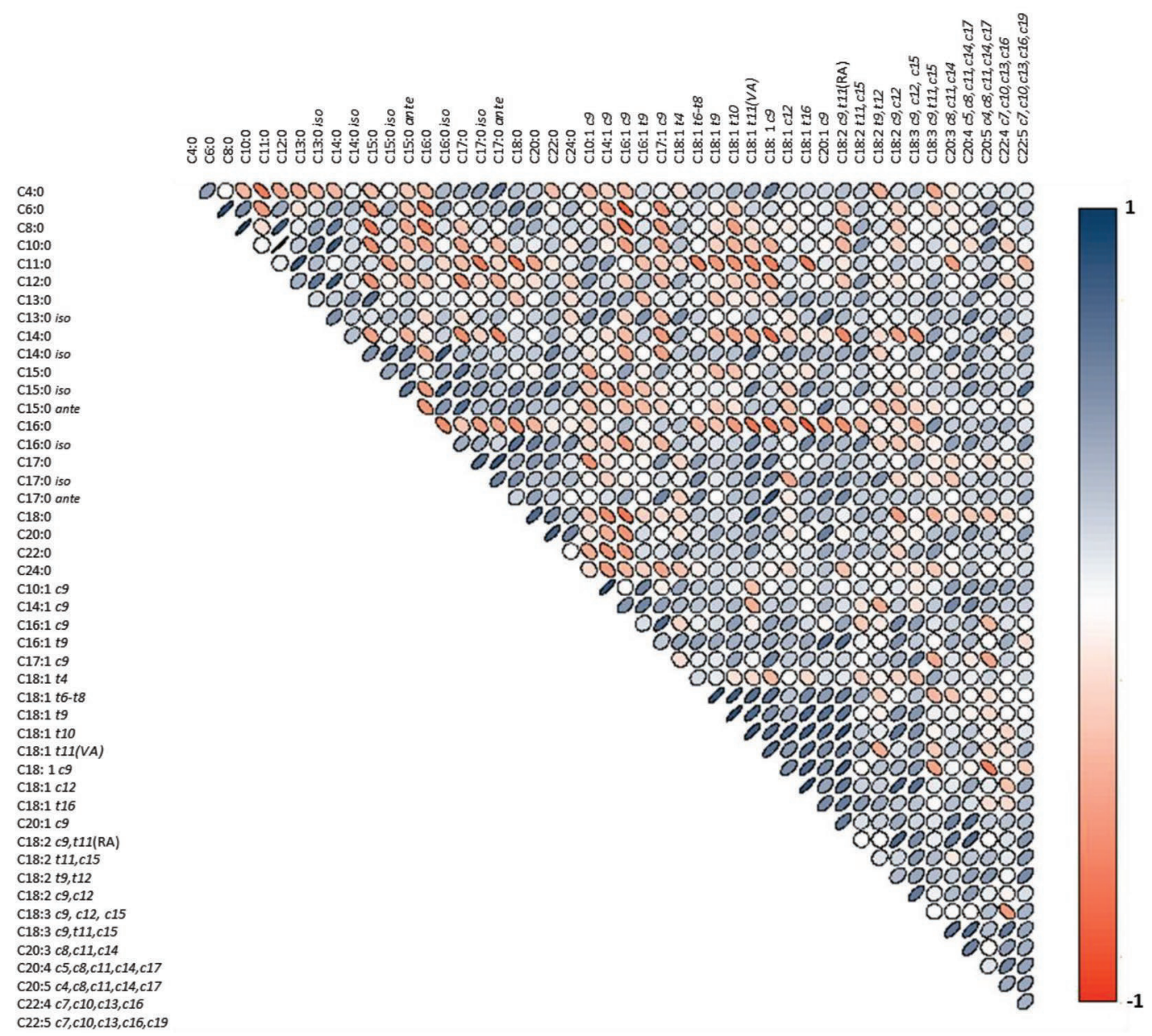

Figure 1. Correlation plot matrices for additive genetic [a] herd-date [b], and residual [c] correlations among single fatty acids. All estimates are expressed as a mean of the marginal posterior density of the parameter. Ellipses colors represent the strength and the direction of the correlation, -1 to 0 to 1 (red to white to blue). $c=c i s ; t=$ trans; VA = vaccenic acid; $\mathrm{RA}=$ rumenic acid. Color version available online. 
C18 fatty acids group showed negative herd-date correlations, with SFA having chains containing 14 to 18 carbon atoms.

The LCFA of the n-3 and n- 6 series were positively correlated for herd-date effect (Figure 1b), and we observed tight clustering between $\mathrm{C} 20: 5$ cis-5, cis-8, cis11,cis-14,cis-17 (eicosapentaenoic acid) and C22:5 cis-7,cis-10,cis-13,cis-16,cis-19 (docosapentaenoic acid) and between $\mathrm{C} 20: 3$ cis-8,cis-11,cis14 (eicosatrienoic acid) and C20:4 cis-5,cis-8,cis-11,cis-14 (arachidonic acid).

In general, the residual correlations among fatty acids due to unknown environmental effects were milder than those observed for the additive genetic and herd-date effects. The highest positive correlations were observed between $\mathrm{C} 10: 0$ and $\mathrm{C} 12: 0$ (0.94), C8:0 and C10:0 (0.88), $\mathrm{C} 12: 0$ and $\mathrm{C} 14: 0$ (0.87), and C6:0 and C8:0 (0.84), and tight clusterings were consistently observed among these fatty acid pairs (Figure 2c). In the C18 fatty acids group, we observed positive correlations of linoleic acid with linolenic acid (0.44) and VA with RA (0.45).

\section{DISCUSSION}

\section{Milk Fatty Acid Profile of Brown Swiss Cows}

Most of the previously published studies have been based on milk fatty acids content predicted from mid-infrared analysis and also when GC analysis was adopted, often only a few of the main fatty acids or fatty acid categories have been reported. The current work provides a comprehensive analysis of the fatty acid profile of milk from Brown Swiss cows, adopting a low detection limit (0.001) able to accurately measure fatty acids contained in minimal amounts in milk fat (between 0.04 and $0.1 \mathrm{~g} / 100 \mathrm{~g}$ of fatty acids). A total of

\section{[b] Herd-date}

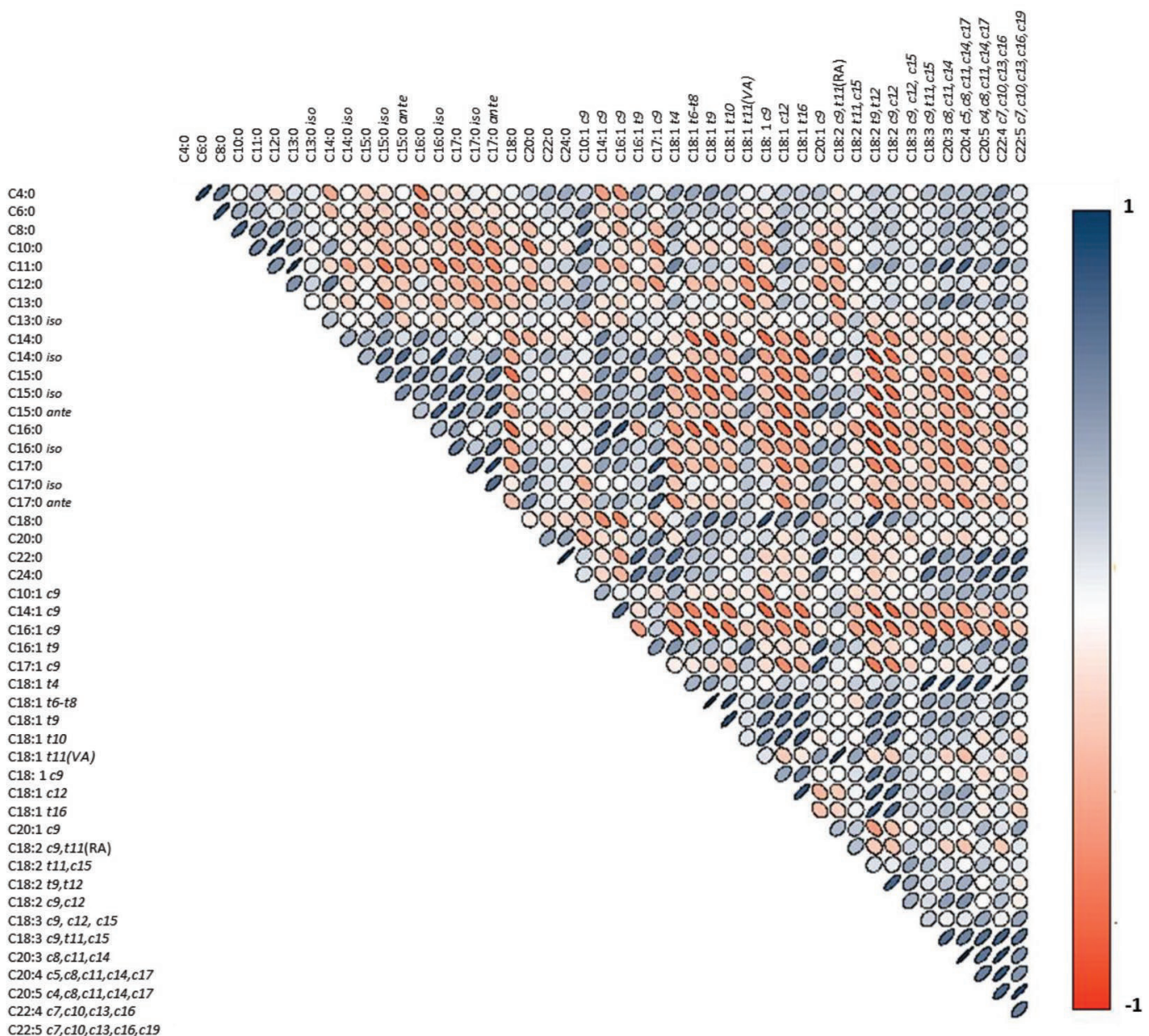

Figure 1 (Continued). Correlation plot matrices for additive genetic [a] herd-date [b], and residual [c] correlations among single fatty acids. All estimates are expressed as a mean of the marginal posterior density of the parameter. Ellipses colors represent the strength and the direction of the correlation, -1 to 0 to 1 (red to white to blue). $c=c i s ; t=$ trans; $\mathrm{VA}=$ vaccenic acid; $\mathrm{RA}=$ rumenic acid. Color version available online. 
47 individual fatty acids, 13 groups of fatty acids, and 5 desaturation indices were evaluated. The phenotypic variations observed for the milk yield, milk fat content, and relative proportions of individual fatty acids (Table 1) are in line with the results from previous studies in Holstein cows (Moate et al., 2007; Bobe et al. 2008; Heck et al., 2012) and other breeds, including Brown Swiss (Kelsey et al., 2003; Soyeurt et al., 2007; Vlaeminck et al., 2006). Likewise, the relative proportions of the SFA, MUFA, PUFA, and stearoyl-CoA desaturase (SCD) indices (Table 2) were consistent with data previously reported by Soyeurt et al. (2006) and Garnsworthy et al. (2010). The present study allowed us also to quantify the proportion of phenotypic variance of fatty acids that can be explained by genetic and herd-date variation and to evaluate the genetic, herd-date, and residual relationships between individual fatty acids.

\section{Heritability and Herd-Date Effect for Milk Fatty Acid Profile}

The fatty acids in milk originate from both the mammary gland uptake of preformed fatty acids from circulating blood (around 60\%) and de novo synthesis within the mammary gland (around 40\%; Chilliard et al., 2000). The precursors for de novo fatty acids synthesis are acetate and butyrate, which are produced during microbial fermentation in the rumen. Butyrate is converted to BHB in the rumen wall (Jensen, 2002). Almost all of the C4:0 to C14:0 odd-chain fatty acids and about a half of the C16:0 in milk fat originate from de novo synthesis in the mammary gland (Shingfield et al., 2013). The rest of the C16:0 and all of the LCFA are taken from the circulating blood lipids, which originate from intestinal absorption (digestion of dietary fat) and

\section{[c] Residuals}

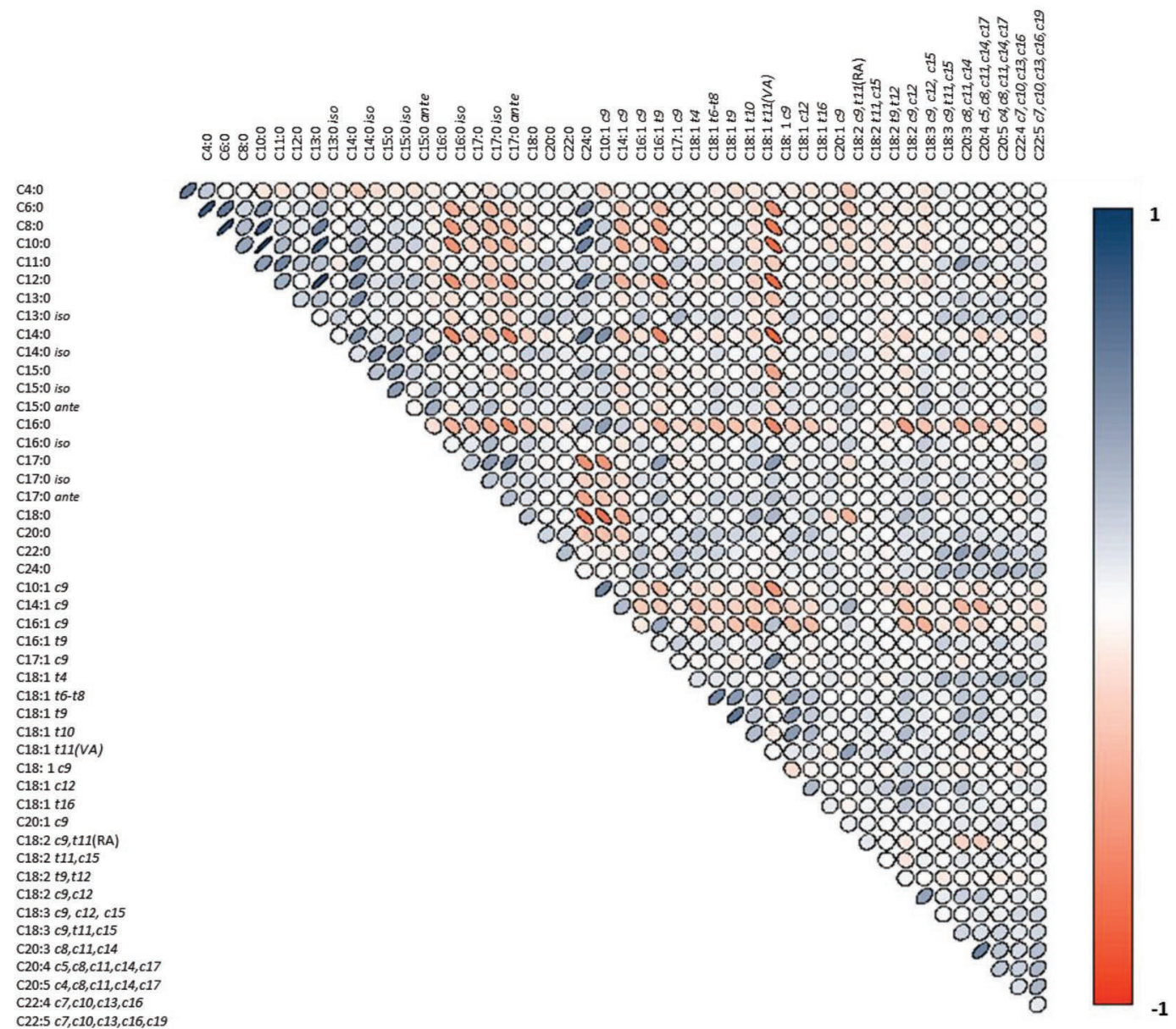

Figure 1 (Continued). Correlation plot matrices for additive genetic [a] herd-date [b], and residual [c] correlations among single fatty acids All estimates are expressed as a mean of the marginal posterior density of the parameter. Ellipses colors represent the strength and the direction of the correlation, -1 to 0 to 1 (red to white to blue). $c=c i s ; t=$ trans; $\mathrm{VA}=$ vaccenic acid; $\mathrm{RA}=$ rumenic acid. Color version available online. 

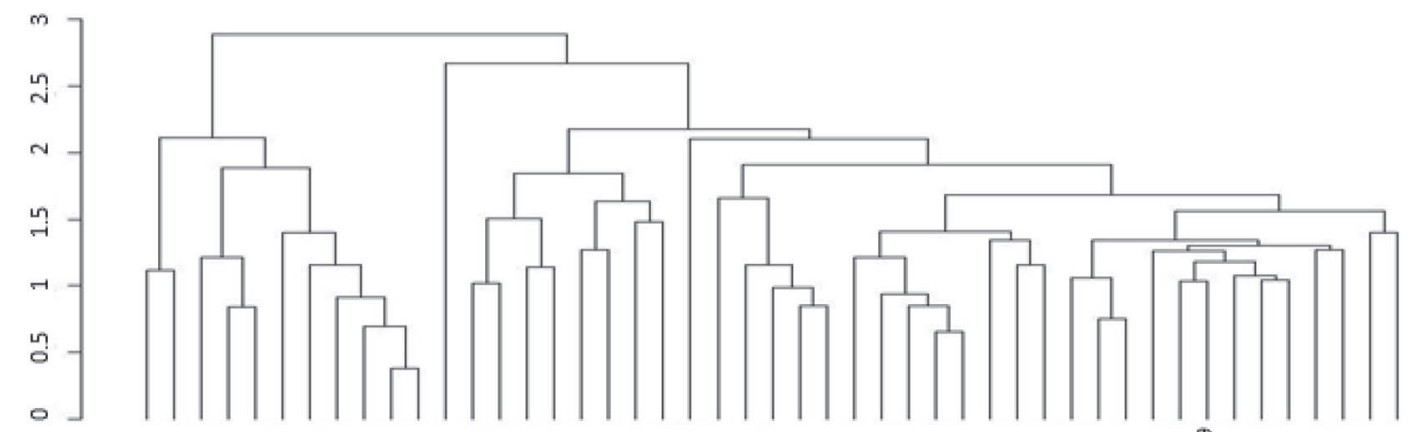

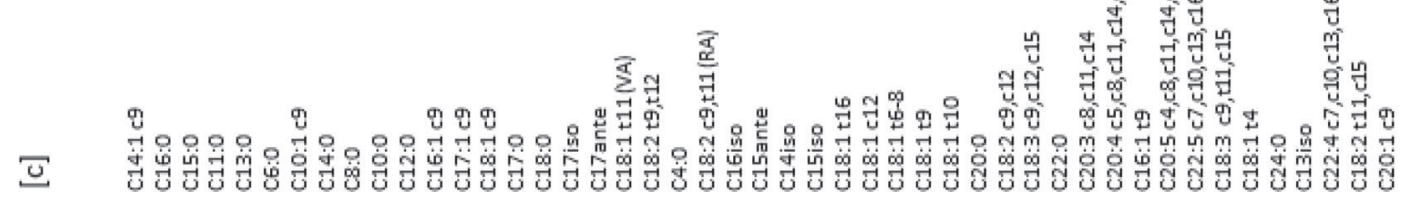
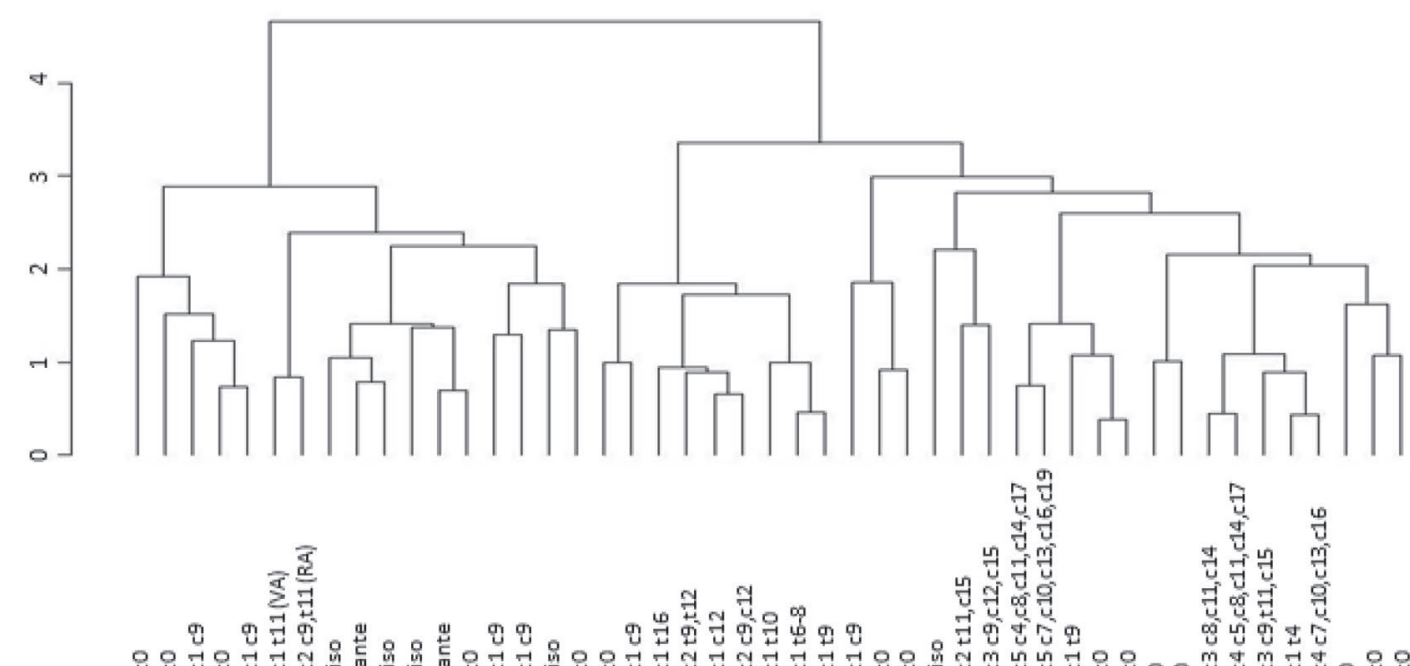

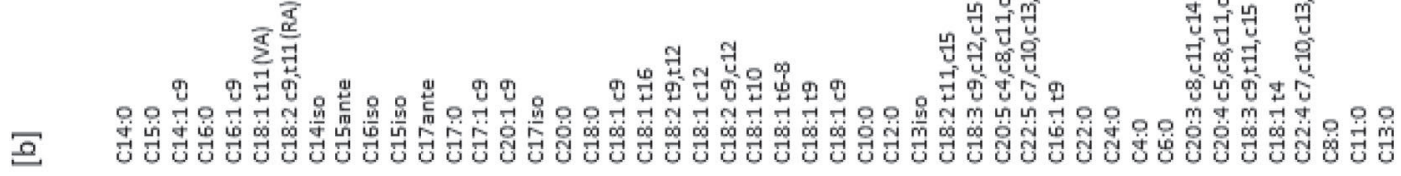
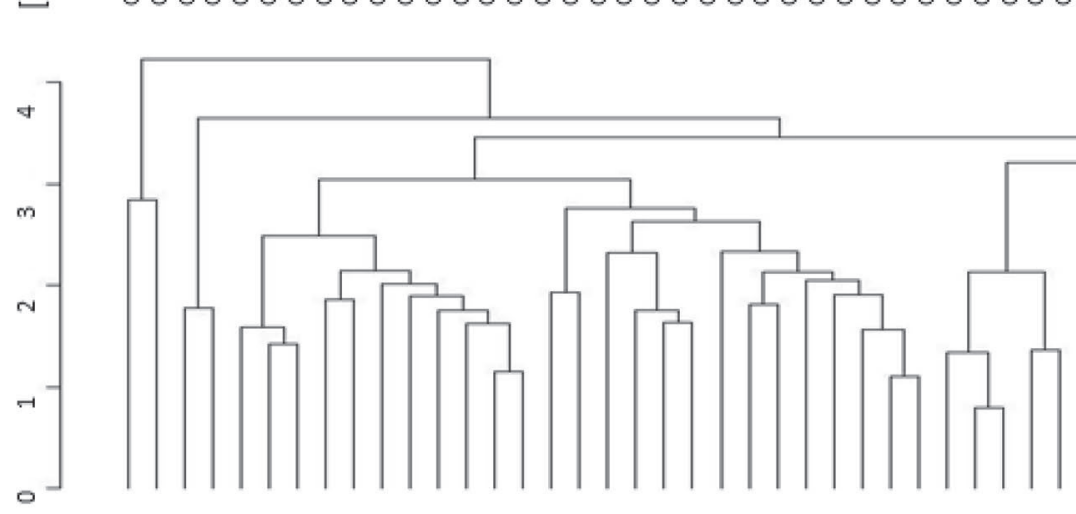
body fat mobilization (Bauman and Griinari, 2003; Shingfield et al., 2010). Nearly half of the C18:1 cis-9 and $70 \%$ of the main CLA isomer (C18:2 cis-9,trans-11) in milk fat are formed via the activity of SCD in the mammary gland, using $\mathrm{C} 18: 0$ and $\mathrm{C} 18: 1$ trans-11, respectively, as precursors (Enjalbert et al., 1998; Shingfield et al., 2013). The odd-chain fatty acids and BCFA found in milk fat might be largely synthesized by rumen bacteria, but some linear odd-chain fatty acids (e.g., C15:0, C17:0) might also be synthesized de novo from propionate in the mammary gland (Vlaeminck et al., 2006).

In the current study, low heritability estimates were obtained for most of the single fatty acids, except for C10:0, C12:0, C16:0, C18:0, C14:1 cis-9, and C16:1 cis9 (Table 3). In previous studies where the individual fatty acids were quantified with GC, the results were commonly expressed as a ratio between the weight of a given fatty acids and the weight of the total fatty acids or milk fat. The heritability estimates reported in these GC-based studies (Bobe et al., 2008; Garnsworthy et al., 2010; Bilal et al., 2014) are comparable to those found in the current paper or somewhat higher (Stoop et al., 2008; Schennink et al., 2008). In contrast, the results from studies based on FTIR predictions (Soyeurt et al., 2007; Bastin et al., 2011, 2013) have commonly been expressed in terms of the weight of a single fatty acid or group of fatty acids per unit of milk $(\mathrm{kg}$ or L) due to the low accuracy of FTIR-based predictions of milk fat content (Ferragina et al., 2015). Data expressed as weight of single or groups of fatty acids per unit of milk would produce heritability estimates for fatty acids similar to those of the milk fat content and often greater than those found for proportion of individual fatty acids on total fatty acid content, as in the current and other GC-based experiments. Actually, it has proven difficult to compare heritability estimates among the various studies because of differences in the analytical methods; the method of expressing fatty acid contents; the database structure (e.g., the number of samples, the utilized breed, the use of first parity or multiparous cows, the use or exclusion of repeated records, and the lactation stage); the utilized statistical model (sire or animal model); and the way in which the heritability is expressed (e.g., intraherd heritability or not).

The results of our analyses indicated that the de novo synthetized fatty acids and SFA were more heritable than the MUFA and PUFA, with a few exceptions. For instance, C4:0 and C6:0 showed very low heritability values (0.033 and 0.039 , respectively). This was expected for $\mathrm{C} 4: 0$, whose production is largely independent from the metabolic condensation of acetyl units and mostly depends on the uptake of rumen-originating
BHB from the blood (Chilliard et al., 2007). Low heritability and a remarkable herd-date effect was also found for C6:0. This fatty acid is formed de novo in the mammary gland by fatty acid synthase; the activity of this enzyme is markedly influenced by dietary factors, and several studies reported that inhibition of de novo lipogenesis was more effective for C6:0 than for the other short-chain fatty acids (Chilliard et al., 2007; Shingfield et al., 2013). This latter finding is consistent with the notable herd-date effect found for this fatty acid in the current study. In addition, the contents of both $\mathrm{C} 4: 0$ and $\mathrm{C} 6: 0$ in the milk triglycerides are regulated by the activity of diacylglycerol acyl-transferase, a key enzyme in triacylglycerol synthesis in the mammary gland, which operates only at the n- 3 position of the fatty acid carbon chain (Jensen, 2002). In Holstein, diacylglycerol acyl-transferase K232A polymorphism was shown to affect milk fatty acid composition (Schennink et al., 2008; Nafikov et al., 2014). The low additive genetic variances found in the current work for C4:0 and C6:0 also reflect the monomorphic nature of the gene encoding diacylglycerol acyl-transferase in Brown Swiss cattle (Conte et al., 2010). The C16:0 showed a moderate heritability and a notable herd-date effect (0.255 and 0.413 , respectively), reflecting that this fatty acid originates partly from de novo synthesis and partly from bloodstream uptake (Garnsworthy et al., 2006; Craninx et al., 2008). High herd-date effects and low heritability estimates were also found for odd-chain fatty acids and BCFA (Table 3), which is consistent with the existing literature (Vlaeminck et al., 2006; Patel et al., 2013). A previous study showed that the herd-date also strongly influenced LCFA, trans fatty acids, C18:1 trans-11 (VA), and C18:2 cis-9,trans-11 (RA), likely reflecting the effect of dietary factors on the contents of these fatty acids in milk fat (Heck et al., 2012). In Holstein cattle, high herd-date effects were reported for VA and RA (Stoop et al., 2008; Duchemin et al. 2013), and the heritability estimates for VA and RA ranged from null to bigger than 0.4 (Bobe et al., 2008, Stoop et al., 2008; Mele et al., 2009).

\section{Heritability and Herd-Date Effect for Desaturation Indices}

The desaturation indices generally showed higher heritability estimates than the individual fatty acid, which is similar to the findings of Bilal et al. (2012) in a Canadian Holstein cattle population. The low heritability estimate obtained for the RA-to- $(\mathrm{RA}+\mathrm{VA})$ ratio reflects the notable herd-date effects (likely reflecting dietary effects) observed for both the precursors and the products of this fatty acid pair. In Holstein cows, Garnsworthy et al. (2010) observed lower heritability 
estimates for RA and VA and a similar heritability value for the RA-to-(RA+VA) ratio compared with those found in the current study. Some of the genetic variability of the milk RA content in Holstein cows reflects the presence of a functional SNP in exon 5 of the gene encoding SCD (Mele et al., 2007; Schennink et al., 2008). The allele frequencies of this SNP in Brown Swiss cattle differ from those of Holstein cattle, and the polymorphism was not found to influence the genetic variability of RA or the RA-to-(RA+VA) ratio of milk fat in this breed (Conte et al., 2010).

The C14 index showed the greatest heritability among the desaturation indices, which is consistent with previous results (Schennink et al., 2008; Mele et al., 2009; Garnsworthy et al., 2010). This index is considered to be a proxy for SCD activity (Lock and Garnsworthy, 2003), because C14:0 is almost completely de novo synthetized and almost all C14:1 cis-9 originates from SCD activity (Bernard et al., 2006). The low heritability found for C14:0 (0.097) in the present study confirms previous reports (Stoop et al., 2008; Mele et al., 2009; Garnsworthy et al., 2010). Notably, C12:0, which is another MCFA sharing common origin with C14:0, showed lower additive genetic, herd-date, and residual variances. Both C14:0 and C16:0 were negatively correlated (Figure 1a) with the main MUFA and PUFA (e.g., C17:1 cis-9; C18:1 cis-9; C18:2 cis9,cis-12, and C18:3 cis-9,cis-12,cis-15), suggesting that the synthesis of C14:0 and C16:0 in the mammary gland is likely to be influenced by the presence of unsaturated fatty acids. This might be consistent with the theory that changes in some aspects of the milk fatty acid content are regulated through a mammary adaptation mechanism to maintain the fluidity of the milk fat and keep its melting point below $39^{\circ} \mathrm{C}$. In fact, unsaturated LCFA that originate from dietary lipids have a lower melting point compared with saturated fat. Thus, to maintain a constant value of milk fat fluidity, the mammary gland may counterbalance increasing fluxes of unsaturated dietary fatty acids by modulating de novo synthesis of SFA (including C14:0 and C16:0) and the C18:0 to C18:1 cis-9 conversion due to the $\Delta^{9}$-desaturase enzyme (Gama et al., 2008).

\section{Genetic, Herd-Date, and Residual Correlations and Clustering of Fatty Acids}

The matrix of the genetic correlations found in the current experiment generally agrees, in biological terms, with the known metabolic pathways of synthesis or transformation shared by individual fatty acids or groups of fatty acids (Figure 1a). The high correlation between short- and medium linear-chain SFA may reflect the activity of the fatty acid synthase mam- mary enzyme. The correlations found between C18:2 cis-9,cis-12 and C18:3 cis-9,cis-12,cis-15 with the longchain PUFA, n6 and n3, are likely to reflect the activity of the mammary elongase and desaturase enzymes, respectively. Mammary elongase activity was also reflected by the correlations found between $\mathrm{C} 18: 0$ and $\mathrm{C} 18: 1$ cis-9 with 20:0 and 20:1 cis-9, respectively (Shingfield et al., 2013). Interestingly, some genetic correlations appeared to be influenced by metabolic processes occurring in the rumen environment. For example, C18:0 was positively correlated with VA and RA, but negatively correlated with C18:2 cis-9,cis-12. All of these fatty acids are involved in the rumen-localized and rumen bacteria-mediated biohydrogenation of dietary C18:2 cis-9,cis-12 (Buccioni et al., 2012). In addition, recent metagenomic studies suggested that some traits related to the activity of the rumen microbiome (e.g., methane emission) may exhibit genetic variability (Hayes et al., 2013; Ross et al., 2012).

The herd-date variance may result from differences between herds in housing, management, or feeding. In the present study, herd-date variance explained the largest part of the total phenotypic variation, especially for the main dietary fatty acids, C18:2 cis-9,cis-12 and C18:3 cis-9,cis-12, cis-15, and their products of biohydrogenation (the trans isomers of C18:1) and elongation (the very long-chain PUFA, n6 and n3). The variabilities associated with the milk fat contents of the odd- and branched-chain fatty acid were also largely explained by the herd-date effect; this was especially true for the linear or branched fatty acids from C15:0 to C17:0, which are considered to be influenced by the forage-to-concentrate ratio of the diet (Vlaeminck, et al., 2006). Similar considerations could be drawn for the long-chain PUFA.

Finally, some groups of fatty acids, particularly those from C6:0 to C14:0 that share a common pathway of de novo synthesis, showed correlations due to unknown environmental factors. In agreement with the work of Vandenplas et al. (2013), this would suggest the existence of genetic variance in micro-environmental sensitivity.

\section{CONCLUSIONS}

The present work provides a comprehensive GC analysis of the fatty acid profile in milk from Brown Swiss cows. Not only fatty acid groups or the most abundant fatty acids were included, but also those present in small amounts and showing benefic effects on human health. The existence and the relevance of genetic determinism for most de novo synthetized fatty acids and SFA were observed, suggesting the possibility to tailor milk fatty acid profile and therefore improve milk fat quality 
through genetic selection. Likewise, a large proportion of phenotypic variance due to herds was observed for most LCFA and unsaturated fatty acid, which was likely influenced by feeding and environmental effects due to the rearing system. The matrix of the genetic and environmental correlations found in the current study allowed us to define the genetic and herd-date relationships among fatty acids sharing common origins or metabolic pathways. Hence, these results allowed us to acquire useful information for the definition of feeding or breeding strategies aimed at the improvement of the nutritional characteristics of milk fat.

\section{ACKNOWLEDGMENTS}

The present study is part of the Cowability-Cowplus project. We thank the Autonomous Province of Trento (Italy) for funding the project, the Italian Brown Swiss Cattle Breeders Association (ANARB, Verona, Italy) for supplying pedigree information, and the Superbrown Consortium of Bolzano and Trento (Trento, Italy) for the support in sampling and recording activities.

\section{REFERENCES}

Bastin, C., N. Gengler, and H. Soyeurt. 2011. Phenotypic and genetic variability of production traits and milk fatty acid contents across days in milk for Walloon Holstein first-parity cows. J. Dairy Sci. 94:4152-4163.

Bastin, C., H. Soyeurt, and N. Gengler. 2013. Genetic parameters of milk production traits and fatty acid contents in milk for Holstein cows in parity 1-3. J. Anim. Breed. Genet. 130:118-127.

Bauman, D. E., and J. M. Griinari. 2003. Nutritional regulation of milk fat synthesis. Annu. Rev. Nutr. 23:203-227.

Bernard, L., C. Leroux, and Y. Chilliard. 2006. Characterization and nutritional regulation of the main genes in the lactating mammary gland. Pages 295-326 in Ruminant Physiology. K. Sejrsen, T. Hvelplund, and M. O. Nielsen, ed. Wageningen Academic Publisher, Wageningen, the Netherlands.

Bilal, G., R. I. Cue, A. F. Mustafa, and J. F. Hayes. 2012. Short communication: Estimates of heritabilities and genetic correlations among milk fatty acid unsaturation indices in Canadian Holsteins. J. Dairy Sci. 95:7367-7371.

Bilal, G., R. I. Cue, A. F. Mustafa, and J. F. Hayes. 2014. Short communication: Genetic parameters of individual fatty acids in milk of Canadian Holsteins. J. Dairy Sci. 97:1150-1156.

Bobe, G., J. A. Minick Bormann, G. L. Lindberg, A. E. Freeman, and D. C. Beitz. 2008. Short communication: estimates of genetic variation of milk fatty acids in US Holstein cows. J. Dairy Sci. 91:1209-1213.

Buccioni, A., M. Decandia, S. Minieri, G. Molle, and A. Cabiddu. 2012. Lipid metabolism in the rumen: New insights on lipolysis and biohydrogenation with an emphasis on the role of endogenous plant factors. Anim. Feed Sci. Technol. 174:1-25.

Casellas, J., J. L. Noguera, J. Reixach, I. Díaz, M. Amills, and R. Quintamilla. 2010. Bayes factor analyses of heritability for serum and muscle lipid traits in Duroc pigs. J. Anim. Sci. 88:2246-2254.

Cattani, M., R. Mantovani, S. Schiavon, G. Bittante, and L. Bailoni. 2014. Recovery of $n-3$ polyunsaturated fatty acids and conjugated linoleic acids in ripened cheese obtained from milk of cows fed different levels of extruded flaxseed. J. Dairy Sci. 97:123-135.

Chilliard, Y., A. Ferlay, R. M. Mansbridge, and M. Doreau. 2000. Ruminant milk fat plasticity: Nutritional control of saturated, polyunsaturated, trans and conjugated fatty acids. Ann. Zootech. 49:181-205.

Chilliard, Y., F. Glasser, A. Ferlay, L. Bernard, J. Rouel, and M. Doreau. 2007. Diet, rumen biohydrogenation and nutritional quality of cow and goat milk fat. Eur. J. Lipid Sci. Technol. 109:828855.

Chilliard, Y., C. Martin, J. Rouel, and M. Doreau. 2009. Milk fatty acids in dairy cows fed whole crude linseed, extruded linseed, or linseed oil, and their relationship with methane output. J. Dairy Sci. 92:5199-5211.

Conte, G., M. Mele, S. Chessa, B. Castiglioni, A. Serra, G. Pagnacco, and P. Secchiari. 2010. Diacylglycerol acyltransferase 1, stearoylCoA desaturase 1 , and sterol regulatory element binding protein 1 gene polymorphisms and milk fatty acid composition in Italian Brown cattle. J. Dairy Sci. 93:753-763.

Craninx, M., A. Steen, H. Van Laar, T. Van Nespen, J. Martín-Tereso, B. De Baets, and J. Fievez. 2008. Effect of lactation stage on the odd- and branched-chain milk fatty acids of dairy cattle under grazing and indoor conditions. J. Dairy Sci. 91:2662-2677.

Danneberger, D., K. Nuernberg, A. Herdmann, G. Nuernberg, E. Hagemann, and W. Kienast. 2013. Dietary PUFA intervention affects fatty acid and micronutrient profiles of beef and related beef products. Foods 2:295-309.

De Marchi, M., M. Penasa, A. Cecchinato, M. Mele, P. Secchiari, and G. Bittante. 2011. Effectiveness of mid-infrared spectroscopy to predict fatty acid composition of Brown Swiss bovine milk. Animal $5: 1653-1658$.

Demment, M. W., and L. H. Allen., ed. 2003. Animal source foods to improve micronutrient nutrition and human function in developing countries. J. Nutr. 133:3875S-4061S.

Dijkstra, J., S. M. van Zijderveldb, J. A. Apajalahtic, A. Banninkd, W. J. J. Gerritsa, J. R. Newboldb, H. B. Perdokb, and H. Berendsa. 2011. Relationships between methane production and milk fatty acid profiles in dairy cattle. Anim. Feed Sci. Technol. 166:590-595.

Duchemin, S., H. Bovenhuis, W. M. Stoop, A. C. Bowman, J. A. M. van Arendonk, and H. P. W. Visker. 2013. Genetic correlation between composition of bovine milk fat in winter and summer, and DGAT1 and SCD1 by season interactions. J. Dairy Sci. 96:592-604.

Enjalbert, F., M. C. Nicot, C. Bayourthe, and R. Moncoulon. 1998. Duodenal infusions of palmitic, stearic or oleic acids differently affect mammary gland metabolism of fatty acids in lactating dairy cows. J. Nutr. 128:1525-1532.

Feng, S., A. L. Lock, and P. C. Garnsworthy. 2004. A rapid lipid separation method for determining fatty acid composition of milk. J. Dairy Sci. 87:3785-3788.

Ferragina, A., G. de los Campos, A. I. Vazquez, A. Cecchinato, and G. Bittante. 2015. Bayesian regression models outperform partial least squares methods for predicting milk components and technological properties using infrared spectral data. J. Dairy Sci. 98:8133-8151.

Fleischer, P., M. Metzner, M. Beyerbach, M. Hoedemaker, and W. Klee. 2001. The relationship between milk yield and the incidence of some diseases in dairy cows. J. Dairy Sci. 84:2025-2035.

Gama, M. A. S., P. C. Garnsworthy, J. M. Griinari, P. R. Leme, P. H. M. Rodrigues, L. W. O. Souza, and D. P. D. Lanna. 2008. Dietinduced milk fat depression: Association with changes in milk fatty acid composition and fluidity. Livest. Sci. 115:319-331.

García-Cortés, L. A., C. Cabrillo, C. Moreno, and L. Varona. 2001. Hypothesis testing for the genetic background of quantitative traits. Genet. Sel. Evol. 33:3-16.

Garnsworthy, P. C., S. Feng, A. L. Lock, and M. D. Royal. 2010. Short communication: Heritability of milk fatty acid composition and stearoyl-CoA desaturase indices in dairy cows. J. Dairy Sci. 93:1743-1748.

Garnsworthy, P. C., L. L. Masso, A. L. Lock, and T. T. Mottram. 2006. Variation of milk citrate with stage of lactation and de novo fatty acid synthesis in dairy cows. J. Dairy Sci. 89:1604-1612.

Gelfand, A. E., and A. F. M. Smith. 1990. Sampling-based approaches to calculating marginal densities. J. Am. Stat. Assoc. 85:398-409. 
Gelman, A., and D. B. Rubin. 1992. Inference from iterative simulation using multiple sequences. Stat. Sci. 7:457-511.

Geweke, J. 1992. Evaluating the accuracy of sampling-based approaches to the calculation of posterior moments (with discussion). Pages 164-193 in Bayesian Statistics. J. O. Berger, J. M. Bernardo, A. P. Dawid, and A. F. M. Smith, ed. Oxford University Press, Oxford, UK.

Geyer, C. J. 1992. Practical Markov chain Monte Carlo. Stat. Sci. $7: 473-483$.

Hayes, B. J., H. A. Lewin, and M. E. Goddard. 2013. The future of livestock breeding: Genomic selection for efficiency, reduced emissions intensity, and adaptation. Trends Genet. 29:206-214.

Heck, J. M., H. J. van Valenberg, H. Bovenhuis, J. Dijkstra, and T. C. van Hooijdonk. 2012. Characterization of milk fatty acids based on genetic and herd parameters. J. Dairy Res. 79:39-46.

Jeffreys, H. 1984. Theory of Probability. 3rd ed. Clarendon Press, Oxford, UK

Jensen, R. G. 2002. The composition of bovine milk lipids: January 1995 to December 2000. J. Dairy Sci. 85:295-350.

Kass, R. E., and A. E. Raftery. 1995. Bayes factors. J. Am. Stat. Assoc. 90:773-795.

Kelsey, J. A., B. A. Corl, R. J. Collier, and D. E. Bauman. 2003 The effect of breed, parity, and stage of lactation on conjugated linoleic acid (CLA) in milk fat from dairy cows. J. Dairy Sci. $86: 2588-2597$.

Krag, K., N. A. Poulsen, M. K. Larsen, L. B. Larsen, L. L. Janss, and B. Buitenhuis. 2013. Genetic parameters for milk fatty acids in Danish Holstein cattle based on SNP markers using a Bayesian approach. BMC Genet. 14:79.

Kramer, J. K., M. Hernandez, C. Cruz-Hernandez, J. Kraft, and M. E. Dugan. 2008. Combining results of two GC separations partly achieves determination of all cis and trans 16:1, 18:1, 18:2 and 18:3 except CLA isomers of milk fat as demonstrated using Ag-ion SPE fractionation. Lipids 43:259-273.

Lock, A. L., and D. E. Bauman. 2004. Modifying milk fat composition of dairy cows to enhance fatty acids beneficial to human health. Lipids 39:1197-1206.

Lock, A. L., and P. C. Garnsworthy. 2003. Seasonal variation in milk conjugated linoleic acid and $\Delta$ 9-desaturase activity in dairy cows. Livest. Prod. Sci. 79:47-59.

Maechler, M., P. Rousseeuw, A. Struyf, M. Hubert, and K. Hornik 2012. Cluster: Cluster analysis basics and extensions. R package version 1.14 .2

Maurice-Van Eijndhoven, M. H. T., S. J. Hiemstra, and M. P. Calus. 2011. Short communication: Milk fat composition of 4 cattle breeds in the Netherlands. J. Dairy Sci. 94:1021-1025.

Mele, M., G. Conte, B. Castiglioni, S. Chessa, N. P. Macciotta, A Serra, A. Buccioni, G. Pagnacco, and P. Secchiari. 2007. Stearoylcoenzyme A desaturase gene polymorphism and milk fatty acid composition in Italian Holsteins. J. Dairy Sci. 90:4458-4465.

Mele, M., R. Dal Zotto, M. Cassandro, G. Conte, A. Serra, A. Buccioni, G. Bittante, and P. Secchiari. 2009. Genetic parameters for conjugated linoleic acid, selected milk fatty acids, and milk fatty acid unsaturation of Italian Holstein-Friesian cows. J. Dairy Sci. 92:392-400.

Mele, M., A. Serra, A. Buccioni, G. Conte, A. Pollicardo, and P. Secchiari. 2008. Effect of soybean oil supplementation on milk fatty acid composition from Saanen goats fed diets with different forage:concentrate ratios. Ital. J. Anim. Sci. 7:297-311.

Moate, P. J., W. Chalupa, R. C. Boston, and I. J. Lean. 2007. Milk fatty acids. I. Variation in the concentration of individual fatty acids in bovine milk. J. Dairy Sci. 90:4730-4739.

Mulligan, F. J., L. O'Grady, D. A. Rice, and M. L. Doherty. 2006. A herd health approach to dairy cow nutrition and production diseases of the transition cow. Anim. Reprod. Sci. 96:331-353.

Nafikov, R. A., J. P. Schoonmaker, K. T. Korn, K. Noack, D. J. Garrick, K. J. Koehler, J. Minick-Bormann, J. M. Reecy, D. E. Spurlock, and D. C. Beitz. 2014. Polymorphisms in lipogenic genes and milk fatty acid composition in Holstein dairy cattle. Genomics $104: 572-581$
Patel, M., E. Wredle, and J. Bertilsson. 2013. Effect of dietary proportion of grass silage on milk fat with emphasis on odd- and branched-chain fatty acids in dairy cows. J. Dairy Sci. 96:390-397.

Poulsen, N. A., F. Gustavsson, M. Glantz, M. Paulsson, L. B. Larsen, and M. K. Larsen. 2012. The influence of feed and herd on fatty acid composition in 3 dairy breeds (Danish Holstein, Danish Jersey, and Swedish Red). J. Dairy Sci. 95:6362-6371.

Rainer, L., and C. J. Heiss. 2004. Conjugated linoleic acid: Health implications and effects on body composition. J. Am. Diet. Assoc. 104:963-968.

Rooke, J. A., J. F. Flockhart, and N. H. Sparks. 2010. Review. The potential for increasing the concentrations of micro-nutrients relevant to human nutrition in meat, milk and eggs. J. Agric. Sci. 148:603-614.

Ross, E. M., P. J. Moate, C. R. Bath, S. E. Davidson, T. I. Sawbridge, K. M. Guthridge, B. G. Cocks, and B. J. Hayes. 2012. High throughput whole rumen metagenome profiling using untargeted massively parallel sequencing. BMC Genet. 13:53.

Rutten, M. J. M., H. Bovenhuis, and J. A. M. van Arendonk. 2010. The effect of the number of observations used for Fourier transform infrared model calibration for bovine milk fat composition on the estimated genetic parameters of the predicted data. J. Dairy Sci. 93:4872-4882.

Schennink, A., J. M. L. Heck, H. Bovenhuis, M. H. P. W. Visker, H. J. F. van Valenberg, and J. A. M. van Arendonk. 2008. Milk fatty acid unsaturation: Genetic parameters and effects of stearoyl-CoA desaturase (SCD1) and acyl CoA:diacylglycerol acyltransferase 1 (DGAT1). J. Dairy Sci. 91:2135-2143.

Shingfield, K. J., L. Bernard, C. Leroux, and Y. Chilliard. 2010. Role of trans fatty acids in the nutritional regulation of mammary lipogenesis in ruminants. Animal 4:1140-1166.

Shingfield, K. J., M. Bonnet, and N. D. Scollan. 2013. Recent developments in altering the fatty acid composition of ruminant-derived foods. Animal 7:132-162.

Soyeurt, H., P. Dardenne, F. Dehareng, G. Lognay, D. Veselko, M. Marlier, C. Bertozzi, P. Mayeres, and N. Gengler. 2006. Estimating fatty acid content in cow milk using mid-infrared spectrometry. J. Dairy Sci. 89:3690-3695.

Soyeurt, H., A. Gillon, S. Vanderick, P. Mayeres, C. Bertozzi, and N. J. Gengler. 2007. Estimation of heritability and genetic correlations for the major fatty acids in bovine milk. J. Dairy Sci. 90:4435-4442.

Stoop, W. M., J. A. van Arendonk, J. M. Heck, H. J. van Valenberg, and H. Bovenhuis. 2008. Genetic parameters for major milk fatty acids and milk production traits of Dutch Holstein-Friesians. J. Dairy Sci. 91:385-394.

Tullo, E., E. Frigo, R. Attilio, R. Finocchiaro, M. Serra, N. Rizzi, A. B. Samorè, F. Canavesi, M. G. Strillacci, M. Prinsen, T. M. Raphaelle, and A. Bagnato. 2014. Genetic parameters of fatty acids in Italian Brown Swiss and Holstein cows. Ital. J. Anim. Sci. $13: 398-403$

van Lingen, H. J., L. A. Crompton, W. H. Hendricks, C. K. Reynolds, and J. Dijkstra. 2014. Meta-analysis of relationships between enteric methane yield and milk fatty acid profile in dairy cattle. J. Dairy Sci. 97:7115-7132

Vandenplas, J., C. Bastin, N. Gengler, and H. A. Mulder. 2013. Genetic variance in micro-environmental sensitivity for milk and milk quality in Walloon Holstein cattle. J. Dairy Sci. 96:5977-5990.

Vlaeminck, B., V. Fievez, A. R. J. Cabrita, A. J. M. Fonseca, and R. J. Dewhurst. 2006. Factors affecting odd- and branched-chain fatty acids in milk: A review. Anim. Feed Sci. Technol. 131:389-417.

White, S. L., J. A. Bertrand, M. R. Wade, S. P. Washburn, J. T. Green, and T. C. Jenkins. 2001. Comparison of fatty acid content of milk from Jersey and Holstein cows consuming pasture or a total mixed ration. J. Dairy Sci. 84:2295-2301.

Woods, V. B., and A. M. Fearon. 2009. Dietary sources of unsaturated fatty acids for animals and their transfer into meat, milk and eggs: A review. Livest. Sci. 126:1-20.

Wright, S. 1922. Coefficients of inbreeding and relationship. Am. Nat. $56: 330-338$ 